\title{
Spatially and temporally restricted expression of Pax2 during murine
} neurogenesis

\author{
HOWARD O. NORNES*, GREGORY R. DRESSLER†, ELZBIETA W. KNAPIK, URBAN DEUTSCH \\ and PETER GRUSS $\ddagger$ \\ Department of Molecular Cell Biology, Max Planck Institute of Biophysical Chemistry, 3400 Gottingen, FRG \\ * On leave from the Department of Anatomy and Neurobiology, Colorado State University, Fort Collins, Colorado 80523, USA \\ †Present address: Laboratory of Molecular Genetics, National Institute of Child Health and Human Development, National Institute of \\ Health, Bethesda, Maryland 20892, USA \\ $\ddagger$ Corresponding author
}

\section{Summary}

The expression of the murine paired-box-containing gene, Pax2, is examined in the developing central nervous system by in situ hybridization. Pax2 expression is detected along the boundaries of primary divisions of the neural tube. Initially, $\mathrm{Pax} 2$ is expressed in the ventricular zone in two compartments of cells on either side of the sulcus limitans and along the entire rhombencephalon and spinal cord. At later times, Pax2 is restricted to progeny cells that have migrated to specific regions of the intermediate zone. In the eye, $P a x 2$ expression is restricted to the ventral half of the optic cup and stalk and later to the optic disc and nerve. In the ear, expression is restricted to regions of the otic vesicle that form neuronal components. The transient and restricted nature of $\operatorname{Pax} 2$ expression suggests that this murine segmentation gene homologue may also establish compartmental boundaries and contribute to the specification of neuronal identity, as do certain Drosophila segmentation genes.

Key words: neurogenesis, paired box, Pax, optic vesicle, otic vesicle, mouse embryology.

\section{Introduction}

The mammalian central nervous system is a highly evolved network of interconnected cells designed to sense, store and process information. Implicit in its design is a precise architecture, the foundation of which is laid down during embryogenesis. How the development of the mammalian nervous system is regulated and what genes encode determining factors for cell and positional specification remain unknown. However, recent experiments with Drosophila embryos demonstrate that certain genes controlling the segmentation of the embryo also affect neurogenesis and, in particular, neuronal identities (Doe et al. 1988a,b; Patel et al. 1989).

Segmentation in Drosophila is controlled by the sequential activation of the gap, pair-rule and segment polarity genes (Nüsslein-Volhard and Wieschaus, 1980; for review see Ingham, 1988; Akam, 1987; Scott and Carroll, 1987). First expressed at the cellular blastoderm stage, the Drosophila pair-rule genes are also expressed during neurogenesis. Thus, a gene that functions in the establishment of a segmented body plan is also required for nervous system development from the neuroectoderm. For example, the fushi tarazu (ftz) protein is expressed in a segmented pattern of seven stripes at the blastoderm stage and fifteen clusters of germ band nuclei in the developing nervous system at the early gastrulation stage (Carroll and Scott, 1985). In fact, a specific neurogenic regulatory element controls $\mathrm{ftz}$ expression at this stage (Hiromi et al. 1985). More recent experiments point to a defined transformation of a neuronal phentoype in $f t z$ mutants (Doe et al. 1988a). Similar observations were also made in temperaturesensitive mutants of the Drosophila pair-rule gene evenskipped (eve) (Doe et al. 1988b). These neurogenic functions are not exclusive to segmentation genes of the pair-rule class, as the segment polarity mutants gooseberry, patched, cell and wingless also exhibit altered neuronal identities (Patel et al. 1989).

Many segmentation and homeotic genes of Drosophila share highly conserved protein domains that have enabled investigators to isolate vertebrate genes with similar domains (for reviews see: Dressler and Gruss, 1988; Wright et al. 1989). The Pax2 gene was identified (Dressler et al. 1990) through its homology to the paired box found amongst the Drosophila segmentation genes paired, gooseberry-proximal, gooseberrydistal, Pox meso and Pox neuro (Bopp et al. 1986; 1989). The $P a x 2$ gene is expressed in the developing excretory 
system (Dressler et al. 1990), a transiently segmented structure of mesodermal origin. In addition, this report describes the spatial and temporal expression pattern of Pax2 during neuronal differentiation in the central nervous system, in defined regions of the otic vesicle, and during morphogenesis and axonal elongation of the optic cup and stalk. Thus Pax2 shares not only the conserved paired domain with some Drosophila segmentation genes, but also a similar biphasic expression pattern during morphogenesis of segmented structures and neurogenesis.

\section{Materials and methods}

The procedure for in situ hybridization is as described in detail in the preceding report (Dressler et al. 1990). Pregnant females were sacrificed at 8-18 days post coitum (p.c.); the day of the vaginal plug was designated as day 0 .

Both antisense and sense mRNA were synthesized from a unique Pax2 cDNA fragment downstream from the paired box sequence to prevent potential cross hybridization with other paired box containing genes (Dressler et al. 1990). In addition, a mouse Hox 3.1 probe was used as a positive control (Breier et al. 1988).

\section{Results}

The expression of Pax 2 was analyzed in various stages of mouse embryogenesis by in situ hybridization. Pax 2 transcripts were detected in embryo tissue sections from days 9-18 post coitum and were restricted to four different epithelial structures: embryonic kidney, neural tube, optic and otic vesicles. Pax2 transcripts were not detected in adult structures examined, including the spinal cord, diencephalon and optic tract (data not shown). The structure of the Pax2 cDNA and its expression in the developing kidney is described in the accompanying paper (Dressler et al. 1990), whereas this paper describes Pax2 expression in the developing nervous system.

At day 8 p.c., Pax 2 RNA could not be detected in any ectodermal or mesodermal structures (data not shown). Pax 2 expression on day 9 of gestation is detected in both the optic and otic vesicles as will be described in detail in the following sections. The earliest detectable expression of Pax2 within the neural tube is during the early stages of neuronal differentiation on day 10 of gestation.

\section{Neural tube \\ Overall pattern}

Beginning at day 10, Pax2 transcripts are expressed along the boundaries of two primary divisions in the neural tube. The rostral limit of $P a \times 2$ expression was at the mesencephalon-rhombencephalon border, the isthmus (Fig. 1A,B arrow) and expression extended through the rhombencephalon and spinal cord, on both sides of the sulcus limitans (Fig. 1C,D). This pattern of expression persists in these cells and their progeny from days 10 to 18 and is described in detail in the transverse plane of the spinal cord during two phases: the periods of (1) neurogenesis and (2) post neurogenesis. Based on $\left[{ }^{3} \mathrm{H}\right]$ thymidine analysis, neurons in the mouse spinal cord originate on days 9 to 13 (Nornes and Carry, 1978; Sims and Vaugh, 1979; McConnell, 1981). During this period, the pseudostratified cells in the neuroepithelium (ventricular zone) are mitotically active. In a precise ventral-to-dorsal order, the cells stop cycling mitotically, and migrate from the margin of the lumen radially to settle in the surrounding mantle layer (intermediate zone). For details on this pattern of cell kinetics in the developing mouse spinal cord refer to Nornes and Carry (1978).

\section{Pax 2 expression during neurogenesis}

On day 10 of gestation, Pax 2 hybridization is detected in two regions of the ventricular zone, one on either side of the ventrodorsal midline, the sulcus limitans (Fig. 2A,B). It is restricted to the basal region (distal to lumen) of the neuroepithelium and is more extensive in the basal plate than in its counterpart in the alar plate. In the basal plate, the silver grains extend further along the ventrodorsal axis as well as further medially towards the apical (luminal) region of the neuroepithelial cells. Pax2 transcripts were never detected in the cells in the ventral $1 / 4$ of the ventricular zone as well as in their progeny which settles in the most ventral and lateral intermediate zone and form motor neurons (Nornes and Carry, 1978).

On day 11.0 of gestation, $\operatorname{Pax} 2$ transcripts in the ventricular zone are still restricted to these same two compartments bordering the sulcus limitans (Fig. 2C,D, arrow). The hybridization is more intense and extensive than on the previous day, particularly in the alar plate component, as it extends further dorsally. By this stage, more cells have migrated from the ventricular zone and the intermediate zone is now present in both the basal and alar plates. A few clusters of silver grains are present in this zone immediately radial to the position of transcripts in the ventricular zone (Fig. 2D arrowheads).

On day 11.5 of gestation, Pax2 transcripts in the ventricular zone are no longer restricted to two compartments on either side of the sulcus limitans but are expressed continuously along the entire dorsal twothirds of this layer (Fig. 2E,F). In the intermediate zone, $\operatorname{Pax} 2$ is expressed in the progeny cells that expressed Pax2 on the previous day and is restricted to two regions extending radially on both sides of the sulcus limitans. In the basal plate, the signal is seen over cells that have settled medial and dorsal to the nonexpressing and earlier formed putative motor neuroblasts (Fig. 2F arrowheads). In the alar plate, transcripts are present over the entire intermediate zone with the highest density of silver grains along its most lateral border.

On day 12 of gestation, the ventricular zone has nearly completely regressed in the basal plate and become thinner in the alar plate (Fig. 2G). In what remains of the ventricular zone, $\operatorname{Pax} 2$ transcripts are still expressed in the dorsal two-thirds; however, the 

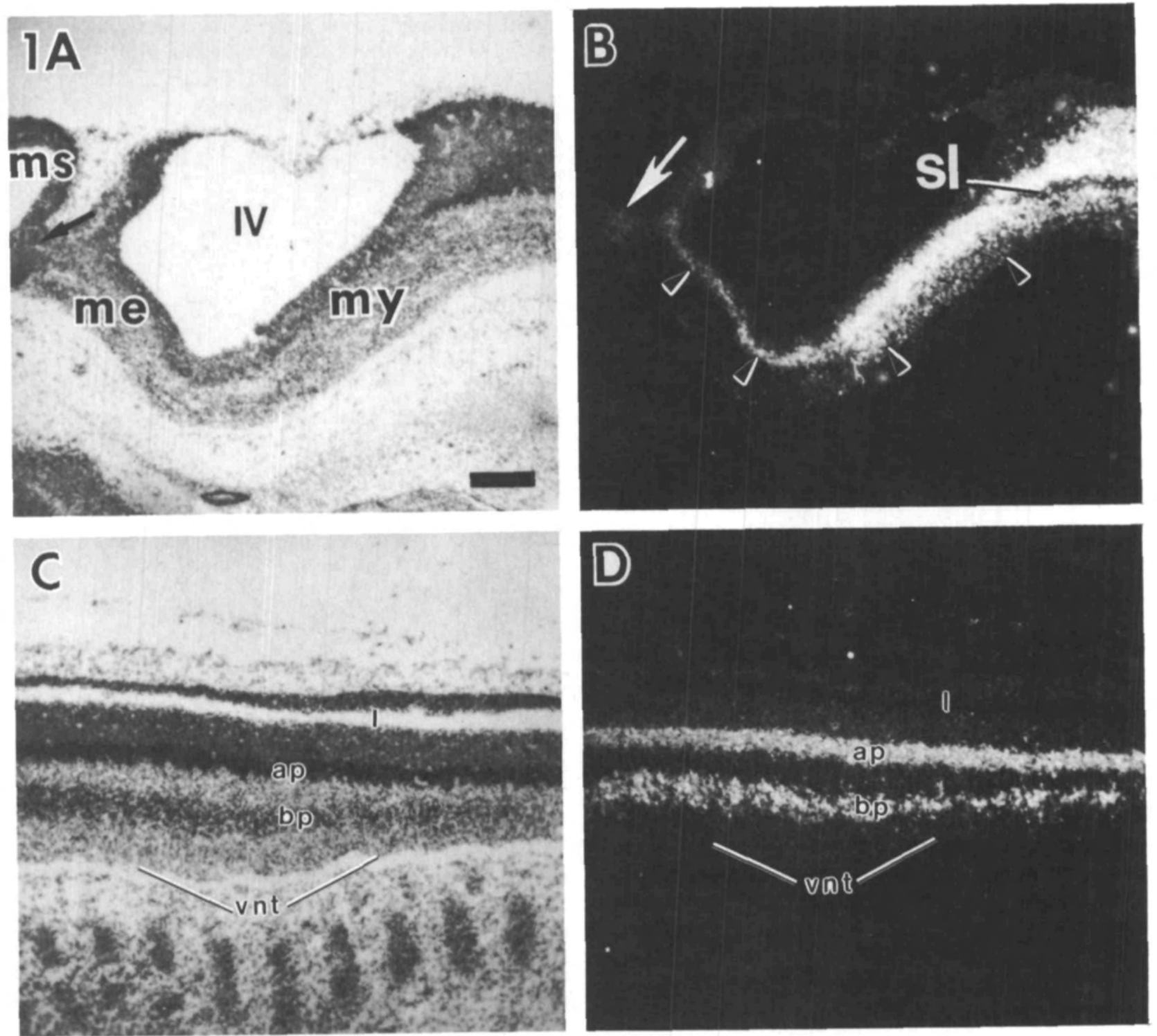

Fig. 1. Expression of Pax2 transcripts along the rostrocaudal axis of the neural tube. Left in all the photographs is rostrad and right is caudad. (A) Parasagittal section of the brain stem hybridized with Pax2 antisense probes, photographed under bright-field illumination. (B) Same field as in A, photographed under dark-field illumination. Note the sharp rostral boundary of silver grains at the rhombencephalic isthmus (arrow) and the continuous longitudinal strip of silver grains from this point and caudally (arrowheads). (C) Parasagittal section of the spinal cord taken from the same animal as A and B, photographed under bright-field illumination. (D) Same field as in C, photographed under dark-field illumination. Note the continuous longitudinal stripes of silver grains along the rostrocaudal axis, one in the basal plate (bp) and the other more dorsally in the alar plate (ap). 1, lumen; me, metencephalon; ms, mesencephalon; my, myelencephalon; sl, sulcus limitans; vnt, ventral border of neural tube; IV, fourth ventricle. Bar, $250 \mu \mathrm{m}$.

density of silver grains is less (arrows, Fig. $2 \mathrm{H}$ ). In the intermediate zone of the basal plate, Pax2 expression is still restricted to the cells medial and dorsal to the nonexpressing pool of motoneuroblasts. In the intermediate zone of the alar plate, the highest amount of Pax2 transcripts is in a band of cells that extends across the midlateral region (Fig. $2 \mathrm{H}$, arrowheads). This set of cells appears to be in the same relative position as those expressing the transcripts in the alar plate on the previous day. Additionally, Pax2 transcripts are detected in the newly formed cells in the most dorsolat- eral alar plate. These cells will form the dorsal region of the dorsal horn, the substantia gelatinosa.

\section{Expression during postneurogenesis}

By day 14 of gestation, all the neurons in the spinal cord have been born and most of them are in their final settling positions. The ventricular zone has regressed and the lumen of the neural tube is now lined by ependymal cells which do not express Pax2 (Fig. 3A, B). Pax2 transcripts are expressed in the same populations of cells as described on the previous days. In the 

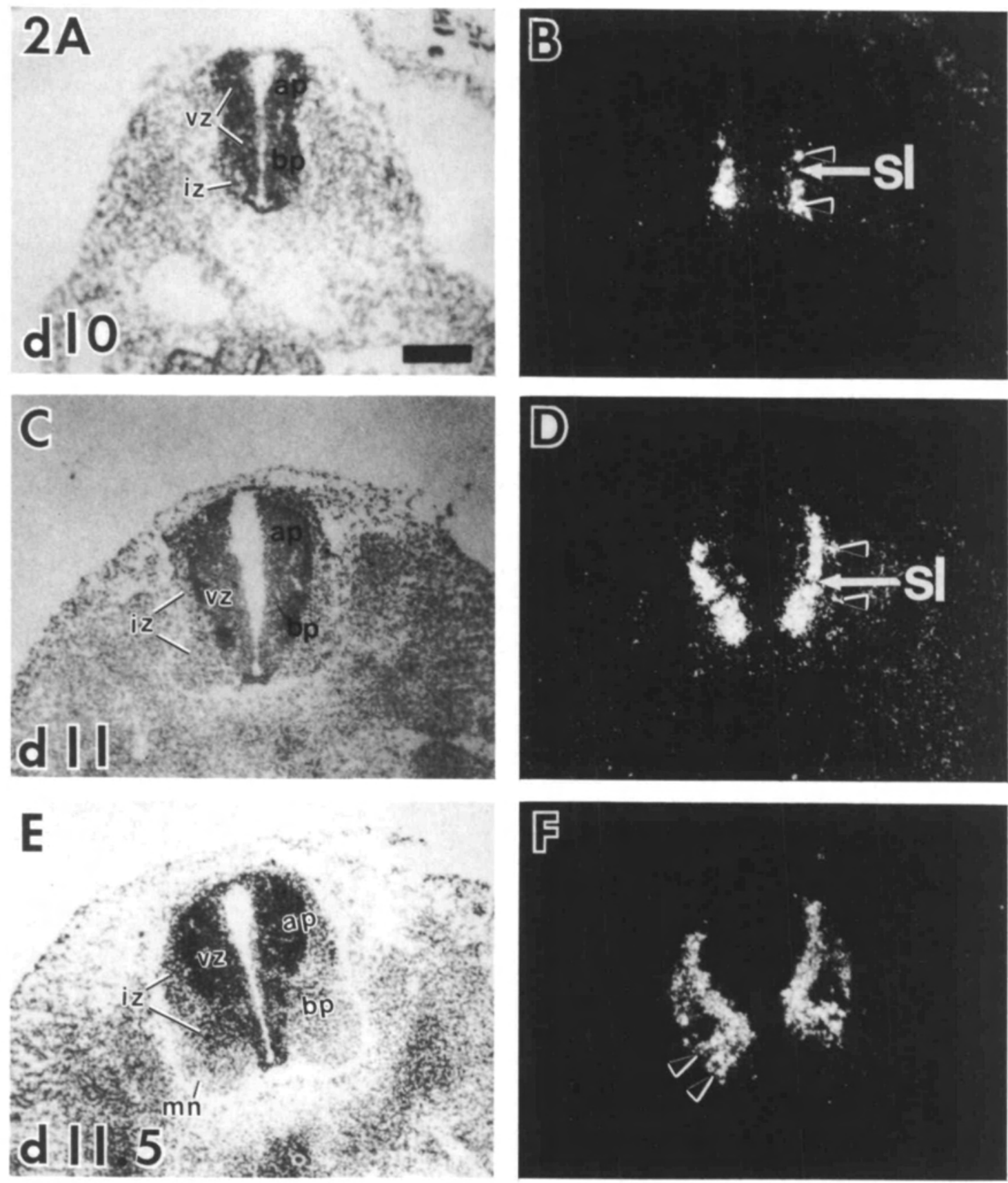

G

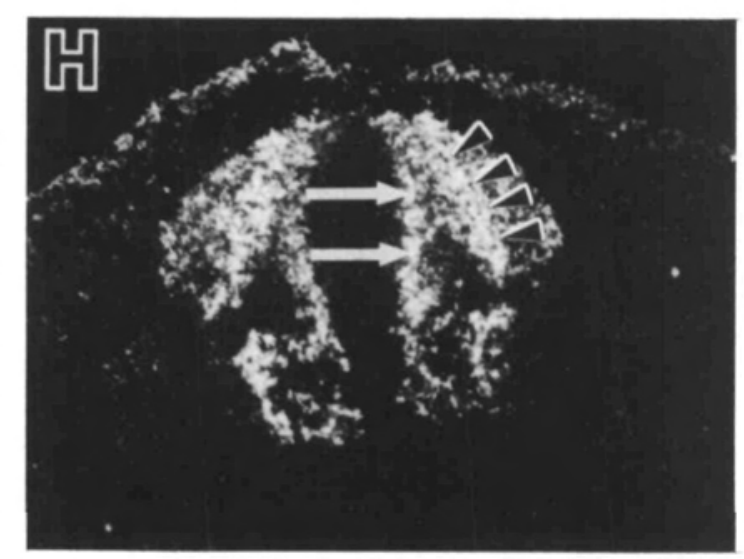


Fig. 2. Pattern of $\operatorname{Pax} 2 \mathrm{mRNA}$ expression in the transverse plane of the embryonic spinal cord during representative periods of neurogenesis. Top of the photographs is dorsal and bottom is ventral. The photographs on the left $(A, C, E, G)$ were photographed under bright-field illumination, and those on the right are the same sections photographed under dark-field illumination. (A,B) A 10day p.c. embryo showing high density of silver grains (arrowheads) in two clusters on either side of the ventrodorsal midline (arrow) and restricted to basal region (distal to lumen) of the neuroepithelium cells in the ventricular zone (vz). (C,D) An 11-day p.c. embryo. The two clusters of expressing cells are still primarily in the basal region of the neuroepithelium in the ventricular zone (vz) with a clear separation at the sulcus limitans (sl, arrow) between the cluster in the basal plate (bp) from that in the alar plate (ap). Some hybridization above background levels is also present in the intermediate zone (iz) lateral to the regions of expression in the ventricular zone (arrowheads). (E,F) An 11.5-day p.c. embryo. In the ventricular zone (vz), the silver grains are still restricted to the basal region of the neuroepithelial cells and, in the intermediate zone (iz), two pools of cells express the transcript: one in the basal plate (arrowheads) dorsal and medial to the putative motor neuroblasts $(\mathrm{mn})$, and the other in most of the alar plate. $(\mathrm{G}, \mathrm{H})$ A 12 -day p.c. embryo. The ventricular zone (vz) has regressed considerably by this stage, nearly completely in the basal plate. Expression is still restricted to the same relative position but is less intense than on the previous days (arrows). In the intermediate zone of the basal plate (bp), expressing cells are in the same relative positions as on the previous day, however, they are more scattered; in the alar plate (ap), expressing cells are in two clusters, one in the same relative position as those observed in the alar plate on the previous day (arrowheads), and another more diffuse pattern of grains over the newly formed cells in the most dorsolateral region. Bar, $250 \mu \mathrm{m}$.

basal plate, $\operatorname{Pax} 2$ hybridization is seen in cells that have settled in the intermediate grey, pars ventralis, a region medial and dorsal to the putative non-expressing motor neuroblasts (Fig. 3A,B arrowheads). In the alar plate, Pax 2 transcripts are in basically the same pattern as on day 12. Pax2 hybridization occurs in the intermediate grey, pars dorsalis (Fig. 3B, arrowheads) and in a region extending medially from the central canal to the most dorsolateral regions (substantia gelatinosa) of the alar plate. The cells in the intermediate central grey still are devoid of Pax2 expression. Since the cells are basically in their final settling positions by day 14 of gestation, the pattern of hybridization on day 18 appears basically the same as described above for day 14 (Fig. 3C,D).

\section{Brain stem}

The pattern of expression in the myelencephalon of the brain stem is essentially similar to that described above for the spinal cord. To illustrate this common pattern, representative transverse sections of the brain stem at the level of the otic vesicle during the early period of neurogenesis are presented. On day 10 of gestation, $P a x 2$ transcripts were detected in the ventricular zone in two clusters on either side of the ventrodorsal midline, presumably the sulcus limitans, and restricted to the outer half to one fourth of the ventricular zone (Fig. 4A,B, arrow). As in the spinal cord, there was no detectable hybridization in the most ventral and dorsal regions of the ventricular zone at this stage.

On day 11 of gestation, the roof plate expands dorsally so the alar and basal plates seemingly open and come to lie in a horizontal plane as illustrated in Fig. 4C,D. Pax2 transcripts are still expressed in the two compartments of the ventricular zone on either side of the dorsoventral midline and also in their progeny in the intermediate zone, which is comparable to the pars ventralis and dorsalis of the spinal cord. The regions of the intermediate zone that will form intermediate central grey and motor columns are again devoid of Pax2 expression.

\section{Otic vesicle}

The otic vesicle develops by a process of invagination of an ectodermal placode in the region of the myelencephalon. The earliest expression of Pax2 transcripts was detected on day 9 of gestation when the otic vesicles were completely separated from the surface ectoderm and flanking the myelencephalon (not shown). On day 10 of gestation, the transcripts are present in the same region of the vesicle; however, now the level of expression is higher (Fig. 4A,B, arrow). The expression is restricted to the side of the vesicle flanking the neural tube. On day 11 of gestation, high-intensity hybridization is located in the more ventral region of the vesicle which forms the saccular and cochlear (neurogenic) portions of the ear (Fig. 4C,D; arrowheads). Pax2 transcripts were not detected in the more dorsal regions of the vesicle, which forms the endolymph sac (open arrowheads). On day 14 of gestation, $\operatorname{Pax} 2$ transcripts were still detected in the saccular and cochlear regions of the developing ear (not shown).

\section{Optic vesicle}

The description of $\operatorname{Pax} 2$ hybridization in the developing eye is divided into two developmental phases: (1) the period of morphogenesis of the optic cup and stalk and prior to axon growth into the stalk, and (2) the period of axogenesis. The first axons from the retina enter the optic stalk at day 12.5 of gestation (Silver and Sapiro, 1981).

\section{Pax2 expression during morphogenesis}

The expression of $\operatorname{Pax} 2$ transcripts in the development of the eye is first detected on day 9 of gestation when the optic vesicle is making contact with the surface ectoderm. As illustrated in Fig. 5A,B, Pax2 hybridization occurred in the most distal region of the optic vesicle, which is apposed to the surface ectoderm. The same section also shows that there is no detectable expression in the neural tube at this early stage (Fig. 5B). Twentyfour hours later on day 10 of gestation, the optic cup is in the process of forming by the invagination of the region of the vesicle that expressed $\operatorname{Pax} 2$ transcripts during the previous day (Fig. 5C). Pax2 hybridization is over the ventral half to two thirds of this invaginating 

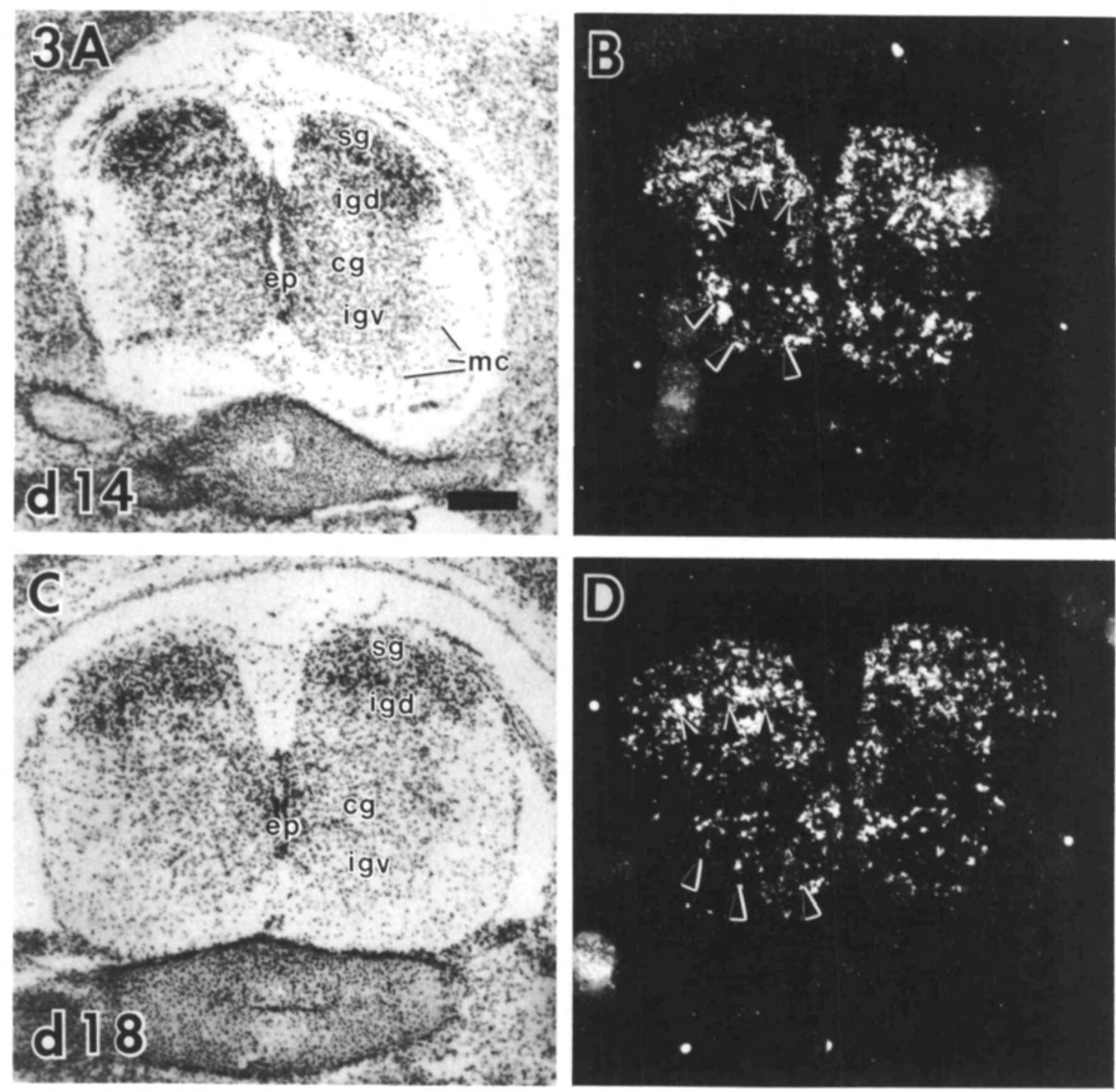

Fig. 3. Pattern of $\operatorname{Pax} 2$ transcripts at 14- and 18-days p.c. in the transverse plane. All the neuroblasts of the spinal cord have been born and most of them are in their final settling positions. Dorsal is top and ventral is bottom. (A) 14-day p.c. embryo, under bright-field illumination. The ventricular zone has completely regressed and ependymal cells (ep) now line the lumen. (B) 14-day p.c. embryo under dark-field illumination. Pax2 expressing cells in the basal plate have settled to form the intermediate grey, pars ventralis (igv, arrowheads), and those in the alar plate form the intermediate grey, pars dorsalis (igd, arrowheads) and the substantia gelatinosa $(\mathrm{sg})$. The central grey $(\mathrm{cg})$ remains unlabeled. (C) 18-day p.c. embryo under bright-field illumination, and (D) the same section photographed under dark-field illumination. Pax2 transcripts are still expressed in the ventral (igv) and dorsal (igd) compartments of the intermediate grey (arrowheads) and in the substantia gelatinosa. mc, motor column. Bar, $250 \mu \mathrm{m}$.

germinal epithelial layer (Fig. 5D, arrow) and the ventral region of the optic stalk (Fig. 5E,F; arrow). The expression ends abruptly at the border with the diencephalon.

By day 11 of gestation, the basic foundation of the eye has formed with the development of the invaginated (inner) layer of epithelium in the cup, which will form the presumptive neural retina, the outer epithelial layer of the cup, which will form the retinal pigment epithelium, and the stalk, which will form the optic nerve (Fig. 5G). The next major morphological event to occur is the formation of the optic fissure in preparation for the guidance pathway for retinal axons. This fissure forms by invagination of the epithelial cells in the most ventral region of the cup and distal optic stalk. Pax2 transcripts appear coincidentally within these regions of invagination. As illustrated in tissue sections from 11 day embryos, high levels of Pax 2 expression are detected in the base of the optic cup (Fig. $5 \mathrm{H}$, arrow) and along the ventral region of the optic stalk extending proximally to the border with the diencephalon (Fig. 5J, arrow).

\section{Pax2 expression during axogenesis}

Representative sections through the eye on days 14 and 

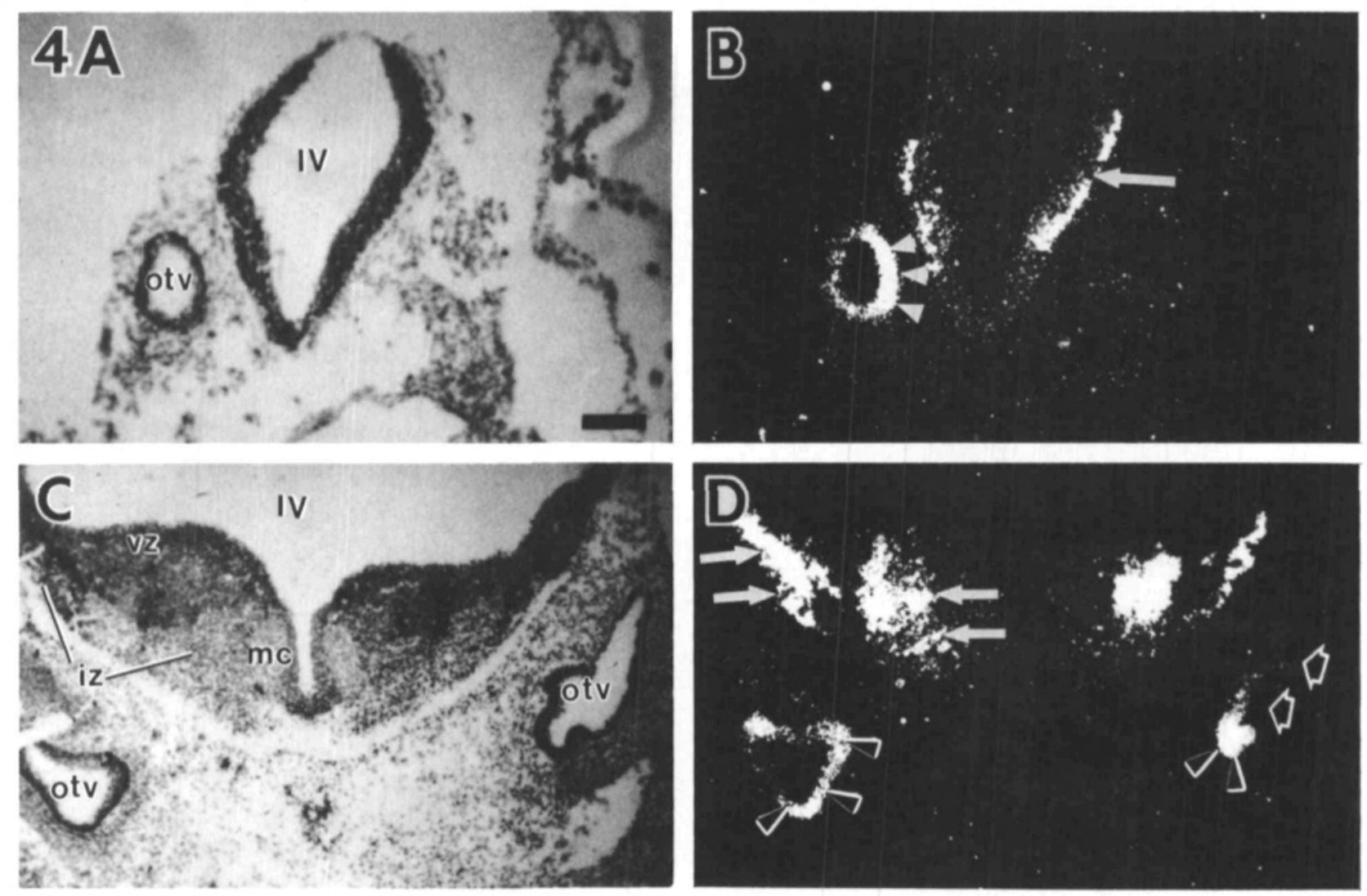

Fig. 4. Pattern of $P a x 2$ mRNA expression in the embryonic brain stem during the period of neurogenesis. Representative transverse sections of the myelencephalon at the level of the otic vesicle (otv); dorsal is top and ventral is bottom. (A) A 10day p.c. embryo, photographed under bright-field illumination. (B) Same section as in A, photographed under dark-field illumination. Pax2 expression is in the same relative position of the ventricular zone as described in Fig. 3 for the spinal cord. Expression is restricted to the basal region (distal to lumen) of the pseudostratified neuroepithelial cells in two clusters on either side of the dorsoventral midline (arrow). In the otic vesicle (otv), expression is restricted to the epithelial cells flanking the neural tube (arrowheads). (C) An 11 day p.c. embryo photographed under bright-field illumination; (D) same section as $\mathrm{C}$ under dark-field illumination. Expressing cells extend in two radial bands (arrows), extending from the lateral $1 / 3$ of the ventricular zone (vz) into the intermediate zone (iz). In the otic vesicle (otv), expressing cells are in the ventral extension of the vesicle (arrowheads) which forms the saccular and cochlear (neurogenic) portions of the ear. The dorsal extension of the vesicle (open arrow) which forms the endolymphatic sac and duct lacks Pax 2 expression. mc, motor column; IV, fourth ventricle. Bar, $250 \mu \mathrm{m}$.

18 illustrate the pattern of expression during axogenesis. The first axons enter the optic stalk on day 12.5 of gestation (Silver and Sapiro, 1981). By day 14 of gestation, the neural retina has two layers; an inner (vitreal side) neuroblastic layer, containing cell bodies of the axons extending to the optic disc and stalk, and an outer layer, containing mitotically active neuroepithelial cells that will give rise to more cells in the inner neuroblastic layer (Fig. 6A). Pax2 hybridization is absent from the neuroblastic layer; however, there is strong expression in the optic disc and extending along the entire optic nerve (Fig. 6B, arrows). Four days later on day 18 , hybridization is not only found in the optic stalk and disc, but also in a thin layer of cells along the vitreal border of the neuroblastic layer (Fig. 6E, arrows). Fig. $6 \mathrm{~F}$ (arrowheads) is a higher magnification of this thin layer of labeled cells along the inner border of the neuroblast layer. Based on the size and location, they appear to be some type of glial cell.

\section{Discussion}

The Pax 2 cDNAs were cloned through their homology to the conserved paired box domain which is found amongst the Drosophila segmentation genes paired, gooseberry-proximal, gooseberry-distal, Pox meso and Pox neuro (Bopp et al. 1986; 1989). Its cDNA and deduced amino acid sequence, as well as its expression pattern in the developing excretory system, are described in the preceding report (Dressler et al. 1990). In this report, we describe its expression patterns during neurogenesis in the brain and spinal cord, and in two special sensory receptors, the eye and ear. The data indicate that Pax2 may function not only during formation of the pro-, meso- and metanephros from inter- 

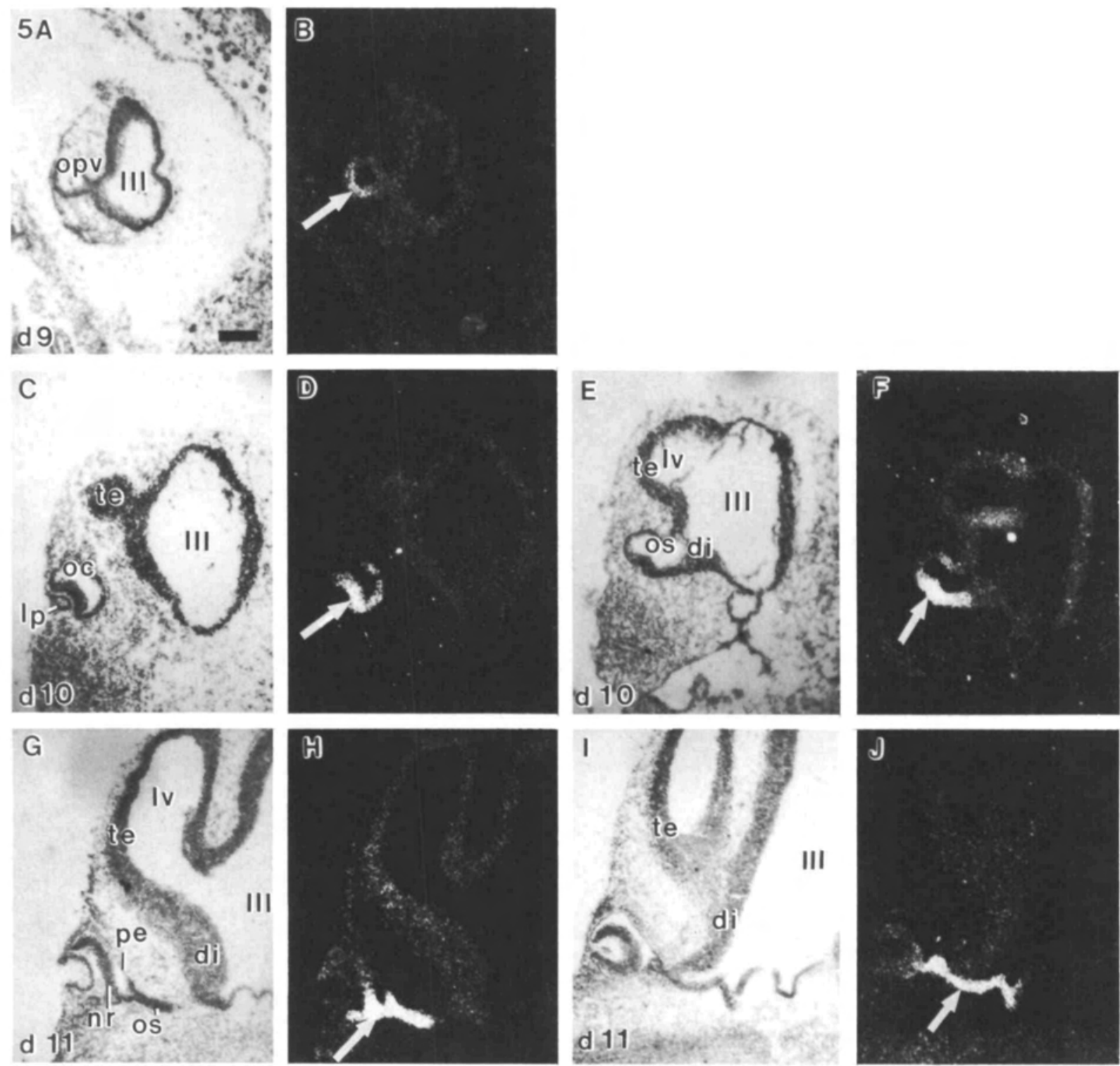

Fig. 5. Pattern of Pax2 expression in the optic stalk and cup during the period of morphogenesis and prior to axon growth out of the neural retina. (A) Section through the optic vesicle (opv) of a 9-day p.c. embryo, photographed under bright-field illumination. Note that the optic vesicle is apposed to the surface ectoderm, however, there is no morphological evidence of a lens placode. (B) Same section as in A, photographed under dark-field illumination. Note the expression (arrow) in the distal region of the vesicle. (C) Section through the optic cup (oc), 10-days p.c. embryo. At this stage the cup has begun to invaginate and the lens placode (lp) has formed. (D) Same section as in C, photographed under dark-field illumination. Note that peak levels of expression (arrow) are in the ventral $2 / 3$ of the invaginating epithelium. (E,F) Same embryo as in $C$ and D, 10-day p.c., illustrating the expression of Pax2 in the optic stalk (os). Note the high expression (arrow) in the ventral region of the stalk and ending proximally to the border with the diencephalon (di). (G) Section through the optic cup, 11 days p.c. embryo, photographed under bright-field illumination. $(\mathrm{H})$ Same section as in $\mathrm{G}$ photographed under dark-field illumination. Note the expression restricted to the base of the optic cup in both the inner and outer epithelial layers (arrow). $(\mathrm{I}, \mathrm{J})$ Same embryo as in $\mathrm{G}$ and $\mathrm{H}, 11$ day p.c., illustrating the expression in the optic stalk. Note the expression (arrow) in the ventral region of the stalk, which extends to the border of the diencephalon (di). lv, lateral ventricle; nr, neural retina; pe, pigment epithelium; te, telencephalon; III, third ventricle. Bar, $250 \mu \mathrm{m}$.

mediate mesoderm, but may have a neurogenic function as well.

\section{Pax2 expression corresponds to longitudinal compartments}

The Pax2 gene is transcribed along boundaries of primary divisions of the neural tube. In early develop- ment, the neural tube is partitioned in the transverse plane at the mesencephalic-rhombencephalic border to form an anterior (prechordal) and posterior (epichordal) division and in a horizontal plane to form a dorsal (alar) and ventral (basal) division (His, 1888; Kingsbury, 1920, 1922; Johnston, 1923; Bergquist and Kallen, 1954; Jarvik, 1980; Jacobson, 1985). That cell 
lineages are restricted in movement to these classically defined divisions in the neural tube has recently been demonstrated by clonal analysis in the 512-cell Xenopus embryo (Jacobson, 1983, 1985; Sheard and Jacobson, 1987). The rostral Pax2 expression boundary in the neural tube is along the mesencephalic-rhombencephalic border at the isthmus and is thus restricted to the posterior division. Within this posterior compartment, Pax2 is expressed along the entire length of the rhombencephalon and spinal cord on both sides of the boundary separating the ventral and dorsal division. This boundary corresponds to the sulcus limitans (His, 1888).

Initially, all the cells in the neural tube are mitotically active (Sauer, 1935, 1959; Langman and Haden, 1970; Sidman et al. 1959; Nornes and Carry, 1978; Altman and Bayer, 1984) and fixed to a particular position at the luminal surface by tight junctions (Lyser, 1968; Holley, 1982). In a precise temporal and spatial pattern and starting at the most ventral region of the basal plate, the cells stop cycling, lose their attachment to the lumen, and migrate radially and settle to form the intermediate layer (mantle layer). While migrating and settling, the cells maintain a relatively constant position with respect to their neighboring cells. Cell birthdates have been determined within each of these functional zones using $\left[{ }^{3} \mathrm{H}\right]$ thymidine labeling and there is a ventral-to-dorsal gradient in their genesis (Nornes and Das, 1974; Altman and Bayer, 1984). In mouse, the motor neurons originate on days 9 to 10 of gestation, followed by those of the intermediate grey on days 10 to 11 , and finally those of the substantia gelatinosa on days 11 to 12 (Nornes and Carry, 1978; Sims and Vaugh, 1979; McConnell, 1981; note that the day of the vaginal plug was designated as day 1 in some references). Pax2 is first expressed on days 10 in the mitotically active neuroepithelial cells on both sides of the ventral and dorsal boundary of the sulcus limitans. Some of these Pax2-expressing cells are in their last mitotic division on day 10, and, by day 11.5, Pax2 is expressed in the region of the intermediate zone where these earlier-labeled cells have settled. The ventral Pax 2 expressing compartment forms the ventral intermediate gray, pars ventralis, and the dorsal compartment forms the pars dorsalis of the intermediate grey region. These two subsets of labeled neurons partition the intermediate grey from the earlier formed motor neuroblasts ventrally and the later forming cells of the substantia gelatinosa dorsally (schematized in Fig. 7). Thus, Pax2 is expressed as compartmental boundaries are established along the longitudinal plane and may function in restricting migration and settling of the cells within the neural tube during this period of neurogenesis.

Morphological evidence shows that the neural tube architecture is established by a series of subdivisions into smaller and smaller cellular domains (His, 1888; Kingsbury, 1920, 1922; Johnston, 1923; Herrick, 1948). According to His the sulcus limitans is one of these major divisions. A fundamental difference between Drosophila and mouse is that compartmental boundaries in the nervous system are established in the transverse plane during Drosophila neurogenesis whereas vertebrates have functionally and morphologically distinct compartments in the longitudinal plane. The segmentation established during Drosophila embryogenesis is retained in the adult by segmentally organized functions in the head, thoracic and abdominal segments. In contrast, the segmented body plan of vertebrates is initially most obvious in mesodermal structures. The segmental organization of neuronal structures is retained in the peripheral nervous system only, whereas the transiently segmented central nervous system is fused into unified longitudinal zones (His, 1888; Herrick, 1948; Bergquist, 1952; Kallen, 1952; Kallen and Lindskog, 1953; Jacobson and Tam, 1982). This additional and rather subtle step in the evolution of vertebrates unifies the function of the sensory and locomotor systems along the entire rostrocaudal axis. Thus, one could predict that a gene specifiying the compartmentalization of the nervous system into functional units would be expressed in a continuous longitudinal manner rather than in reiterated transverse compartments as evident in Drosophila. The Drosophila gene Pox neuro is expressed in a few neuroblasts per segment and later on in their progeny in the peripheral as well as in the central nervous system (Bopp et al. 1989). The difference in the establishment of functional compartments during neurogenesis in Drosophila and mouse may be reflected by the seemingly different expression patterns of Pax 2 and comparable Drosophila segmentation genes at comparable stages. Therefore Pax 2 and possibly Pox neuro may have similar functions in defining cell lineages during neurogenesis.

\section{Pax2 expression in the optic and otic vesicles}

The expression of Pax2 in the optic vesicle within the context of the classical divisions in the neural tube is not as clear. In the early stages (day 9 to 11 ), Pax2 is expressed in the ventral half of both the optic cup and stalk. The optic vesicle develops by evagination of the prosencephalon, and it is not clear if this outpouching is included in the anterior or posterior division of the neural tube. Some classical schemes include the optic chiasma within the posterior compartment of the neural tube (Jarvik, 1980). By clonal analysis in Xenopus, the eye is included within the anterior compartment, although a boundary separating the dorsal from the ventral cup and stalk is revealed (Jacobson, 1983). At the very least, it is clear that Pax2 expression is restricted to a particular compartment in the ventral half of the developing optic cup.

The otic vesicle is a mosaic of specific regions that give rise to specific elements of the developing ear $(\mathrm{Li} e t$ al. 1978; D'Amico-Martel and Noden, 1983; Noden, 1988), and Pax2 transcripts are found in all neurogenic regions of the vesicle. In the early stages, $\operatorname{Pax} 2$ transcripts are seen on the medial cells flanking the rhombencephalon, and it is within this region that some cells bud-off to form the acoustico-cochlear ganglia (Li et al. 1978). At later stages, the only region of the vesicle not expressing the transcripts is the most dorsally projecting 

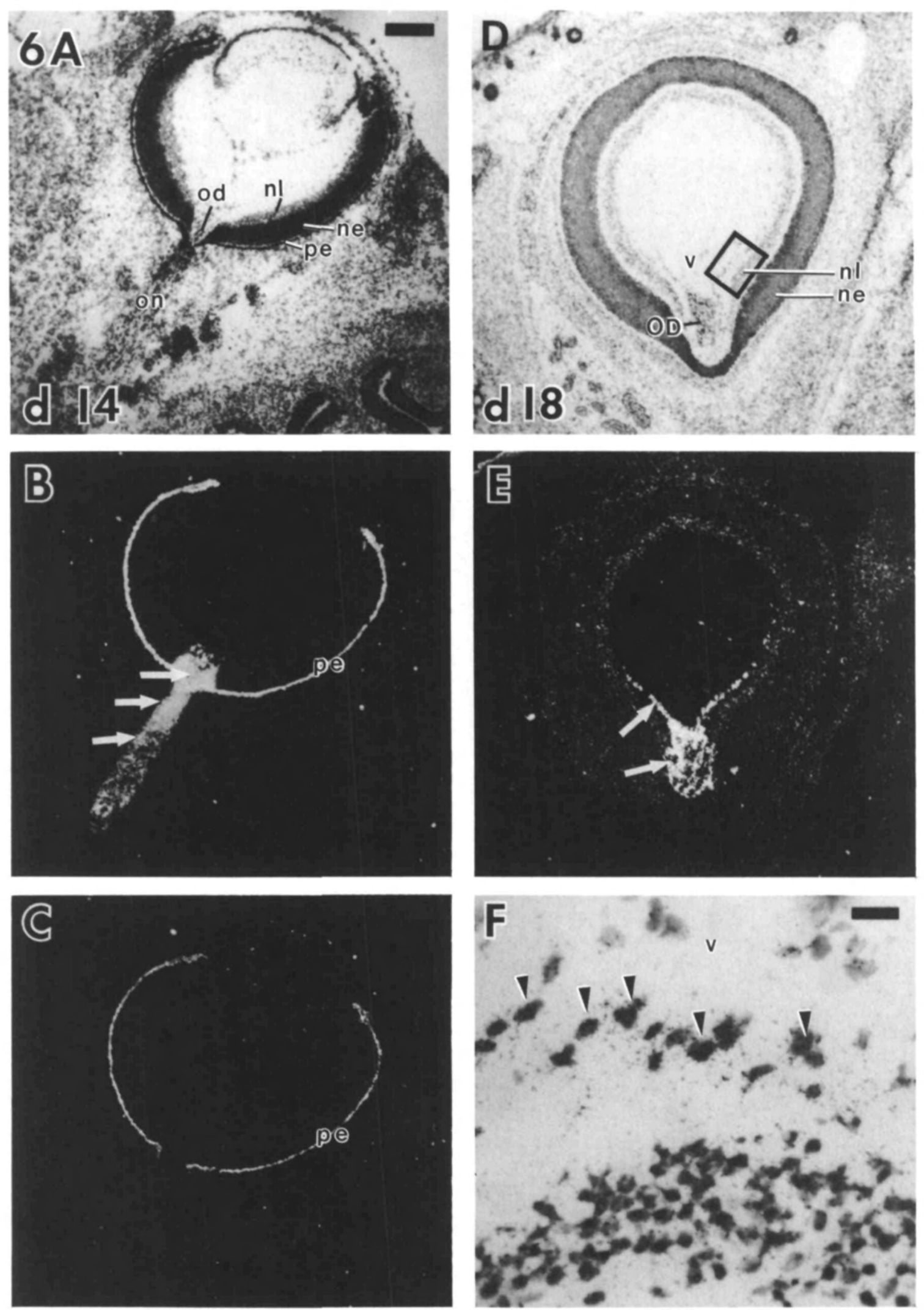

outpouching which forms the non-neurogenic endolymphic duct. There is variability of intensity of expression within the vesicle; however, a more comprehensive

analysis is necessary in order to relate specific regions of high intensity of expression to specific structures in the developing ear. 
Fig. 6. Pattern of Pax2 expression in the optic cup and stalk during the period of axogenesis. (A) Sections through the optic disc (od) and optic nerve (on) at 14 days p.c., hybridized with antisense mRNA and photographed under bright-field illumination. Note that by this stage, the neuroblastic layer $(\mathrm{nl})$ has formed in the inner layer of the neural retina (ne). (B) Same section as A, photographed under dark-field illumination. Note the expression within the optic disc and along the optic stalk (arrows). The bright layer of illumination around the perimeter of the optic cup is an artifact from the pigment epithelium (pe). (C) Control section, adjacent tissue section to $B$, hybridized with sense Pax2 probe and photographed under dark-field illumination. Note the lack of silver grains above background levels in all the structures, and again the artifactual illumination from the pigment epithelium. (D) Tissue section through the optic disc at 18 days p.c., hybridized with antisense Pax2 mRNA and photographed under bright-field illumination. (E) Same section as D, photographed under dark-field illumination. Note the expression over the optic disc and extending into the thin layer of cells in the innermost region of the neuroblastic layer (arrows). (F) High magnification of the neuroblastic layer $(\mathrm{nl})$ of the neural retina indicated by the square in D. Note the silver grains over the small cells (arrowheads) on the innermost region of the neuroblastic layer. $\mathrm{v}$, vitreous. Bar, A-E, $250 \mu \mathrm{m}, \mathrm{F}, 25 \mu \mathrm{m}$.

\section{Pax 2 and other murine genes}

Of the many vertebrate genes isolated by sequence homology to Drosophila developmental control genes, nearly all are expressed in the central or peripheral nervous system. The genes of the murine Hox family were cloned by homology to Drosophila homeotic genes (reviewed by Holland and Hogan, 1988; Wright et al. 1989). Like their Drosophila homologues, they are expressed in particular rostrocaudal regions of the neural tube. In contrast to $\operatorname{Pax} 2$, some Hox genes are expressed as early as day 7.5 in neural ectoderm (Gaunt, 1987) and most are expressed by day 8 . In general, Hox gene expression predates neuronal differentiation in the spinal cord by at least one full day. Also, the genes of the Hox 1 and 2 cluster exhibit variable anterior boundaries of expression in the neural tube that correlate with gene order on the chromosome (Gaunt et al. 1988; Graham et al. 1989). Thus, it has been proposed that Hox genes may regionally delineate position along the anterior-posterior axis.

Of particular interest for the interpretation of the Pax2 expression pattern are other mouse genes that were also cloned via their homology to Drosophila segmentation genes. Expression of the mouse engrailed-like genes demarcates specific regions of the brain and spinal cord in the transverse plane. En-1 expression in cells of the neural tube (Davidson et al. 1988) partially overlaps with the Pax2 expression pattern in the ventrolateral region of the basal plate. En-2 expression is limited to the brain, centered around the rhombencephalic isthmus and metencephalon and does not extend caudally (Davis et al. 1988). However, En-2 expression at 8.5 days appears in the more dorsal half of the neuroepithelium and clearly demarcates the developing hindbrain along the transverse axis (Davis et al.

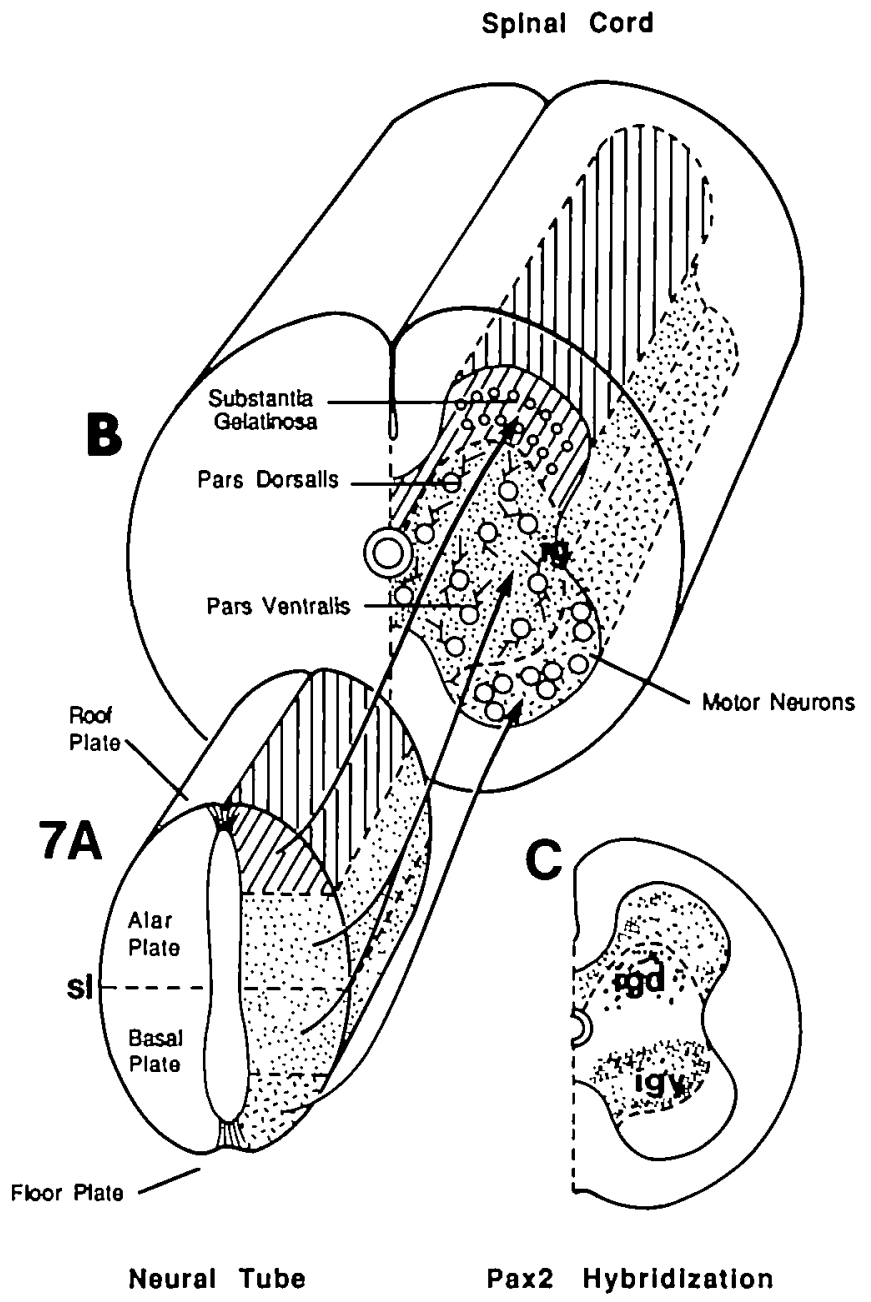

Fig. 7. Schematized illustration of the longitudinal organization of the neural tube. Arrows indicate how each of these longitudinal columns gives rise to...(B) the longitudinally organized functional systems in the adult spinal cord. In early development, the lateral plate is partitioned into a basal (ventral) and alar (dorsal) half at the sulcus limitans (sl). The most ventral column in the basal plate gives rise to motor systems, the two columns on either side of the sulcus limitans give rise to the intermediate grey region (ig), and the most dorsal column gives rise to the substantia gelatinosa. The motor neurons are the output system, the intermediate grey neurons form intersegmental and long ascending systems, and the substantia gelatinosa neurons form an intersegmental system within this same functional layer (Brown, 1981). (C) Schematized pattern of Pax2 expression in the adult spinal cord. Initially, Pax2 is expressed on either side of the sulcus limitans and later in their progeny in the pars ventralis (igv) and pars dorsalis (igd) of the intermediate grey. The latest forming Pax2 expressing cells settle in the substantia gelatinosa and the medial intermediate grey.

1988). Recent data with a mouse evenskipped related gene also indicate very localized expression at the midline along the entire longitudinal axis of the developing spinal cord (Bastian and Gruss, 1990). Thus, it is possible that particular neuron types in a functionally repeated unit are specified by expressing a unique 
combination of segmentation gene homologues. From the evidence derived from certain Drosophila pair-rule and segment polarity gene mutants (Patel et al. 1989; Doe et al. $1988 a, b)$, we would predict that the murine segmentation gene homologues can also regulate early neurogenic events such as cell birth, cell identity and stereotypic axon growth in the longitudinally organized cellular compartments of the neural tube.

As noted in the preceding paper (Dressler et al. 1990), there may be as many as four different Pax2 transcripts and at least two forms of the protein. At present, we cannot discern whether the expression of one particular form of mRNA and protein correlates with ectoderm or mesoderm derived structures. In addition, different forms of $\operatorname{Pax} 2$ protein may have multiple functions depending on the local cellular environment and its interaction with other factors.

We thank S. Geisendorf for technical assistance, R. Altschäffel for excellent photography and D. Carlson for artwork. H.O.N. was supported in part by $\mathrm{NIH}$ grant NS21309-03A1 and G.R.D. is an Alexander von Humboldt fellow. This work was supported by the Max Planck Gesellschaft.

\section{References}

Aкам, M. (1987). The molecular basis for metameric pattern in the Drosophila embryo. Development 101, 1-22.

Altman, J. And Bayer, S. A. (1984). The development of the rat spinal cord. In Advances in Anatomy, Embryology, and Cell Biology, vol. 85 (ed. F. Beck, W. Hild, J. van Limborgh, R. Ortmann, J. E. Pauly and T. H. Schiebler). New York: SpringerVerlag.

Bastian, H. and Gruss, P. (1990). A murine even-skipped homologue, Evxl, is expressed during early embryogenesis in a biphasic manner. EMBO J. 9, 1839-1852.

BERGQUIST, H. (1952). Studies on the cerebral tube in vertebrates. The neuromeres. Acta zool. 33, 117-187.

Bergquist, H. J. AND Kallen, B. (1954). Notes on the early histogenesis and morphogenesis of the central nervous system. $J$. comp. Neurol. 100, 627-659.

Bopp, D., Burri, M., Baumgartner, S., Frigerio, G. and Noll, $M$. (1986). Conservation of a large protein domain in the segmentation gene paired and in functionally related genes of Drosophila. Cell 47, 1033-1040.

Bopp, D., Jamet, E., Baumgartner, S., Burri, M. and Noll, M. (1989). Isolation of two tissue-specific Drosophila paired box genes, Pox meso and Pox neuro. EMBO J. 8, 3447-3457.

Breier, G., Dressler, G. R. ANd Gruss, P. (1988). Primary structure and developmental expression pattern of Hox 3.1, a member of the Hox 3 homeobox gene cluster. EMBO J. 7, 1329-1336.

Brown, A. G. (1981). Organization in the Spinal Cord. SpringerVerlag: Berlin.

Carroll, S. D. AND SCott, M. P. (1985). Localization of fushi tarazu protein during Drosophila embryogenesis. Cell 43, 47-57.

D'Amico-Martel, A. and Noden, D. M. (1983). Contributions of placodal and neural crest cells to avian cranial peripheral ganglia. Am. J. Anat. 166, 445-468.

Davidson, D., Graham, E., Sime, C. and Hill, R. (1988). A gene with sequence similarity to Drosophila engrailed is expressed during the development of the neural tube and vertebrae in the mouse. Development 104, 305-316.

Davis, C. A., Noble-Topham, S. E., Rossant, J. and Joyner, A. L. (1988). Expression of the homeo box-containing gene En-2 delineates a specific region of the developing mouse brain. Genes \& Dev. 2, 361-371.

Doe, C. Q., Hiromi, Y., Gehring, W. J. and Goodman, C. S. (1988a). Expression and function of the segmentation gene fushi tarazu during Drosophila neurogenesis. Science 239, 170-175.

Doe, C. Q., Smouse, D. and Goodman, C. S. (1988b). Control of neuronal fate by the Drosophila segmentation gene even-skipped. Nature 333, 376-378.

Dressler, G. R., Deutsch, U., Chowdhury, K., Nornes, H. O. AND Gruss, P. (1990). Pax2, a new murine paired-box-containing gene, and its expression in the developing excretory system. Development 109, 787-795.

Dressler, G. R. AND GRUSS, P. (1988). Do multigene families regulate vertebrate development? Trends in Genetics 4, 214-219.

GAUNT, S. J. (1987). Homeobox gene Hox 1.5 expression in mouse embryos: earliest detection by in situ hybridization is during gastrulation. Development 101, 51-61.

Gaunt, S. J., Sharpe, P. T. And Duboule, D. (1988). Spatially restricted domains of homeo-gene transcripts in mouse embryos: relation to a segmented body plan. Development 104 , supplement, $169-179$

Graham, A., Papaplopolu, N. and Krumlauf, R. (1989). The murine and Drosophila homeobox gene complexes have common features of organization and expression. Cell 57, 367-378.

Herrick, C. J. (1948). The Brain of the Tiger Salamander. University of Chicago Press.

Hiromi, Y., Kuroiwa, A. And Gehring, W. J. (1985). Control elements of the Drosophila segmentation gene fushi tarazu. Cell 43, 603-613.

His, W. (1888). Zur Geschichte des Gehirns; sowie der centralen peripherischen Nervenbahnen beim menschlichen Embryo. Abh. K. Sachs. Ges. Wiss. Math.-Phys. Kl. 14, 341-372.

Holland, P. W. H. and Hogan, B. L. M. (1988). Expression of homeo box genes during mouse development: a review. Genes \& Dev. 2, 773-782.

Holley, J. A. (1982). Early development of the circumferential axonal pathway in mouse and chick spinal cord. J. comp. Neurol. 205, 371-382.

INGHAM, P. W. (1988). The molecular genetics of embryonic pattern formation in Drosophila. Nature 335, 25-34.

JACOBSON, A. G. AND TAM, P. P. L. (1982). Cephalic neurulation in the mouse embryo analyzed by SEM and morphometry. Anat. Record 303, 375-396.

JaCOBSON, M. (1983). Clonal organization of the CNS of the frog. J. Neurosci. 3, 1019-1038.

JACOBSON, M. (1985). Clonal analysis and cell lineages of the vertebrate central nervous system. Ann. Rev. Neurosci. 8, 71-102.

JARVIK, E. (1980). Basic Structure and Evolution of Vertebrates, vol. 2. Academic Press.

Johnston, J. B. (1923). Further contributions to the study of the evolution of the forebrain. J. comp. Neurol. 35, 337-481.

Kallen, B. (1952). On the significance of neuromeres and similar structures in vertebrate embryos. J. Embryol. exp. Morph. 57, $11-118$.

KALLEN, B. AND LindsKog (1953). Formation and disappearance of neuromery in Mus musculus. Acta anat. 18, 273-282.

KingsBury, B. F. (1920). The extent of the floor plate of His and its significance. J. comp. Neurol. 32, 113-135.

KingsBury, B. F. (1922). The fundamental plan of the vertebrate brain. J. comp. Neurol. 34, 461-491.

Langman, J. and Haden, C. C. (1970). Formation and migration of neuroblasts in spinal cord of the chick embryo. J. comp. Neurol. 138, 419-431.

Li, C. W., Van de Water, T. R. and Ruben, R. J. (1978). The fate mapping of the eleventh and twelfth day mouse otocyst: an in vitro study of the sites of origin of the embryonic inner ear sensory structures. J. Morph. 157, 249-268.

LYSER, K. M. (1968). Early differentiation of motor neuroblasts in the chick embryo as studied by electron microscopy. Devl Biol. $17,117$.

MCCONNELL, J. A. (1981). Identification of early neurons in brain stem and spinal cord. I. An autoradiographic study in the mouse. J. comp. Neurol. 200, 273-288.

NODEN, D. (1988). Interactions and fates of avian craniofacial mesenchyme. Development 103, supplement, 121-140. 
Nornes, H. O. and CarRY, M. (1978). Neurogenesis in spinal cord of mouse: an autoradiographic analysis. Brain Res. 159, 1-16.

NoRnes, H. O. AND DAS, G. D. (1974). Temporal pattern of neurogenesis in spinal cord of rat. I. An autoradiographic study: time and sites of origin and migration and settling patterns of neuroblasts. Brain Res. 73, 121-138.

Nússlein-Volhard, C. and Wieschaus, E. (1980). Mutations affecting segment number and polarity in Drosophila. Nature 287, 795-801.

Patel, N. H., Schafer, B., Goodman, C. S. and Holmgren, R. (1989). The role of segment polarity genes during Drosophila neurogenesis. Genes and Dev. 3, 890-904.

Sauer, F. C. (1935). Mitosis in the neural tube. J. comp Neurol. $62,377-405$.

SaUer, M. E. (1959). Radioautographic study of the location of newly synthesized deoxyribonucleic acid in the neural tube of the chick embryo: evidence for intermitotic migration of nuclei. Anat. Record 133, 456.

Scott, M. P. ANd Carroll, S. B. (1987). The segmentation and homeotic network in early Drosophila development. Cell 51 , $689-698$.
Sheard, P. AND Jacobson, M. (1987). Clonal restriction boundaries in Xenopus embryos demonstrated with two intracellular lineage tracers. Science 236, 851-854.

Sidman, R. L., Miale, I. L. and Feder, N. (1959). Cell proliferation and migration in the primitive ependymal zone: an autoradiographic study of histogenesis in the nervous system. Expl Neurol. 1, 322-333.

Silver, J. ANd Sapiro, J. (1981). Axonal guidance during development of the optic nerve: the role of pigmented epithelia and other extrunsic factors. J. comp. Neurol. 202, 521-538.

Sims, T. J. AND Vaugh, J. E. (1979). The generation of neurons involved in an early reflex pathway. J. comp. Neurol. 183, 707-719.

Wright, C. V. E., Cho, K. W. Y., Oliver, G. and De Robertis, E. M. (1989). Vertebrate homeodomain proteins: families of region-specific transcription factors. TIBS 14, 52-56. 